\title{
A família Civita e a imprensa na América Latina
}

\author{
The Civita Family and the press in Latin America \\ La familia Civita y la prensa en América Latina
}

\author{
Aline de Jesus Nascimento ${ }^{1 *}$ \\ ${ }^{1}$ Universidade Estadual de São Paulo, Assis/SP - Brasil
}

SCarzanella, Eugenia. Uma editora italiana na América Latina: o Grupo Abril (décadas de 1940 a 1970). Campinas. Editora da Unicamp, 2016.

Escrever acerca da trajetória dos fundadores até a consolidação da Abril é tarefa que exige fôlego. Em meados do século XX, os seus criadores remodelaram os nichos editoriais na América Latina, principalmente no que tange ao caso brasileiro. Além do tradicional almanaque e das mais diversas coleçôes de fascículos, os produtos foram diversificados em vários suportes impressos não se limitando apenas às revistas, destinadas aos mais diversos públicos. A Abril segmentou o mercado de impressos e levou às bancas o mais variado tipo de revistas, que iam do esporte à moda, do gerenciamento e decoração da casa à informação semanal, enfim, uma diversidade de conteúdos que acabavam por agradar diferentes leitores e interesses, o que permitiu à empresa construir um verdadeiro império no campo editorial e tornar as bancas de jornais locais de informação e entretenimento. Uma empresa com tal renome não passaria impune aos historiadores, há uma gama de trabalhos acadêmicos acerca das principais revistas produzidas pela empresa, cada qual com sua metodologia.

O livro da professora de História da Universidade de Bolonha, Eugenia Scarzanella, seguiu uma linha interessante ao se basear na trajetória dos italianos pertencentes à família Civita na segunda metade do século XX. Especialista em América Latina, o livro representa sua primeira investida na empresa Abril. Sem deixar de entrelaçar as publicações da editora com o contexto político vigente, Scarzanella esmiuçou, com maestria, uma análise que levou em conta a experiência da Abril na Argentina, no Brasil e no México. Portanto, apesar da editora Abril constituir-se objeto comumente pesquisado, a autora contribui para as relaçóes internacionais de um empreendimento que

DOI: http://dx.doi.org/10.1590/2237-101X02104313.

Resenha recebida em 5 de novembro de 2018 e aceita para publicação em 24 de junho de 2019.

* Mestranda da Universidade Estadual de São Paulo / Departamento de História, campus Assis, Assis/SP Brasil. Bolsista Fapesp, processo no 2017/15451-9. E-mail: lini_nascimento@hotmail.com. ORCID: https:// orcid.org/0000-0002-0094-8550. 
não afetou apenas o campo econômico, mas também o cultural. Dessa maneira, o título da obra por si já fornece indícios do que o leitor irá encontrar ao se debruçar no texto: a experiência de uma editora italiana na América Latina.

Cabe destacar dois pontos: a data de lançamento da tradução em português foi oportuna, visto que o atual cenário da editora não é mais promissor como o das décadas anteriores; a edição brasileira foi publicada pela Editora Unicamp, renomada por disseminar grandes títulos na área acadêmica.

Além do obstáculo da escassez de estudos que contemplem a trajetória da editora nos três países, outro desafio da pesquisa concerne às fontes. A fragmentação de documentos da editora Abril, que se encontram espalhados em diferentes bibliotecas e arquivos históricos, elencados na apresentação do livro, exigiu o empenho da pesquisadora não apenas na recolha, mas também no estabelecimento de uma linha de raciocínio diante de tantas frações. Também, a ausência de indícios fez com que Scarzanella levantasse diversas fontes para cobrir possíveis brechas na história. As fontes orais foram contribuições relevantes para o trabalho da historiadora. Além de compartilharem lembranças dos membros da família Civita, os testemunhos dos funcionários da empresa forneceram informações que não puderam ser acessadas nos escassos documentos oficiais.

A obra privilegia os primeiros anos da editora na Argentina, ao evidenciar como ocorreu a investida da empresa e quais foram as obras de mais destaque naquele país. A questão das relaçóes étnicas e de como os italianos ocuparam espaço desse empreendimento na Argentina foi delineado pela autora e representa um novo olhar acerca da empresa. O livro, desse modo, contribui para novas perspectivas acerca dessa grande empresa que náo se limitou apenas a um espaço geográfico.

O Brasil aparece como pano de fundo, quando a Abril constituiu-se numa empresa autônoma, mas que soube se apropriar de determinadas publicaçóes de sua vizinha. Ao México foram destinadas poucas páginas no final do livro. A partir da atuação da família Civita na América Latina, o livro está dividido em seis capítulos com títulos claros acerca do que cada componente irá abordar. Acrescenta-se dois recursos interessantes: o índice onomástico e o caderno de imagens, elementos pós-textuais de grande relevância para quem quer realizar uma rápida consulta de revistas citadas no decorrer dos capítulos.

Scarzanella abordou os passos iniciais dos fundadores das empresas, a família Civita, desde o momento que fizeram parte da estatística dos exilados que se espalharam nos territórios da América por causa dos regimes totalitários entre 1920 e da Segunda Guerra Mundial que eclodiram na Europa. Cabe lembrar que uma parcela desses exilados era pertencente à classe social média alta, com elevados recursos econômicos e culturais. A atividade editorial da família Civita dentro do território latino-americano iniciou-se na Argentina com Cesare, empenhado em publicaçóes de revistas em quadrinhos. Uma rede de relações e parcerias, firmadas por Cesare, na qual estavam envolvidos contatos com a comunidade judai- 
ca e italiana na Argentina, possibilitou um leque de novos financiadores e leitores. Em 1944, a Abril argentina publicou uma revista em pequeno formato da Disney: El Pato Donald. Trabalhar nesse local não significou apenas um privilégio econômico comparado a outros empregos no setor, simbolizava a possibilidade de compartilhar um ambiente dinâmico, jovem, culto e divertido.

Vittorio seguiu o caminho do irmão e, com os direitos autorais da Disney, publicou no Brasil, em junho de 1950, o Pato Donald, marcando o momento inicial da empresa que dominaria as bancas em poucos anos. A sede da editora sempre foi São Paulo, estado que se destacava do ponto de vista econômico e que então contava pouco mais de dois milhôes de habitantes. $\mathrm{O}$ mundo do jornalismo, assim como o da cultura e dos intelectuais, era largamente dominado pelo eixo Rio de Janeiro/São Paulo e a cidade foi uma aposta do fundador que acabou por se revelar bastante acertada.

Scarzanella estabeleceu os traços comuns entre os dois países, que não se limitaram apenas pela escolha do mesmo nome para a editora. $\mathrm{O}$ desenvolvimento paralelo da Abril no Brasil e na Argentina prosseguiu por todos os anos de 1950. O caso da revista de fotonovelas Capricho merece destaque nessa relação devido ao seu grande sucesso. Lançada em 1952, a revista foi dirigida por uma colaboradora da Abril argentina, a fim de contribuir para o lançamento de novas publicações nesse gênero. Após uma mudança de formato e o início da publicação de histórias completas em cada número, o periódico chegou a uma tiragem de $500 \mathrm{mil}$ cópias e uma versão em espanhol passou a ser distribuída na Argentina.

O segredo da Abril consistia em colocar no mercado novos produtos com publicações diferenciadas e destinadas a determinadas faixas de consumidores, em uma velocidade imposta pelas nuances do mercado editorial. Assim, em 1959, foi lançada em São Paulo a primeira revista de moda, Manequim, que utilizava material fotográfico proveniente de Buenos Aires.

Ainda na década de 1960, Parabrisas na Argentina foi grande sucesso relacionada ao desenvolvimento da indústria automobilística no país. O êxito acarretou no aumento de sua periodicidade - de mensal para semanal - a fim de estar mais presente nas bancas. Foi rebatizada como Corrida (1966) e Raúl Horacio Burzaco foi convidado para dirigi-la. Em agosto de 1960, a Abril de São Paulo lançou a revista Quatro Rodas, sob direção do jornalista Mino Carta, nos moldes da publicação argentina, igualmente especializada em turismo e automóveis.

Em 1961 surgiu nas bancas Claudia, publicação homônima à argentina lançada em 1957. Seguindo os moldes de Marie Claire, Grazia e Ladies' Home Journal, esse semanal feminino foi de imediato grande sucesso. Destinado a donas de casa, explorou o uso de fotografia e publicidade nas suas páginas. No caso brasileiro, foi a primeira revista feminina que trouxe no título o nome de uma mulher. Os periódicos renovaram o gênero e sempre estiveram em sintonia com o crescimento da urbanização e das camadas médias. Porém, progressivamente ambas as revistas, brasileira e argentina, se distancia- 
ram, ao adequar-se aos poucos cada qual a sua realidade nacional. Com grande sucesso até os dias atuais, no Brasil, Cláudia, destinada à mulher casada, deu origem a subprodutos como Casa Cláudia.

A Abril firmou-se no mercado brasileiro em função de projetos grandiosos e inovadores. Para garantir maior eficiência na vendagem, a editora criou uma rede de distribuição própria, comprou bancas e financiou jornaleiros para os quais organizou também cursos de formação. A editora brasileira antecipou-se à argentina no mercado de enciclopédias e fascículos com A Biblia mais bela do mundo (1965), Os pensadores (1974), Os economistas (1982).

Pode-se levantar hipóteses de que a Abril brasileira pôde usufruir da vantagem de melhores relaçóes com o poder público, mesmo com as dificuldades ligadas à limitação da liberdade da imprensa, fator que não se repetiu com a ditadura na Argentina. $\mathrm{O}$ regime militar brasileiro foi provavelmente para os empresários um interlocutor mais estável e mais hábil na gestão da economia em relação ao regime militar argentino, que fez as empresas naquele país "navegar[em] em águas difíceis, adaptando-se à mudança brusca de governos, à pretensão recorrente dos militares de impor à censura (e com ela a moral católica e conservadora) e à hostilidade dos seguidores de Perón (de direita e de esquerda), em guerra permanente entre si” (p.113).

A irmá brasileira lançou Realidade, em 1966, e Veja, em setembro de 1968. A censura impediu a circulação da primeira durante dois anos devido aos conteúdos consi- derados ofensivos (sexo, aborto, divórcio). O momento de lançamento da última não foi feliz porque, em dezembro do mesmo ano, foi decretado o Ato Institucional no 5, com o qual o regime militar suspendia as garantias constitucionais. Entre 1975 e 1976, Veja teve que se submeter à aprovação prévia da censura e evitar tratar de uma lista de temas proibidos. Inclusive, de acordo com a historiadora, a demissão do diretor da revista, Mino Carta, teria sido uma exigência da ditadura, informação contestada de acordo com a versão do Roberto Civita (ALMEIDA, 2009, p. 151). Veja conseguiu sobreviver à ditadura e quando a editora brasileira comemorou 50 anos foi a revista com mais exemplares vendidos no país.

A Abril argentina não teve a mesma sorte, seus semanários de atualidade foram alvos de forte censura, houve intimidação e violência contra jornalistas, proprietários e tipógrafos. Em 1975, a organização de direita Aliança Anticomunista Argentina (Triple A) explodiu, diante do prédio da editora, uma bomba lança-panfletos contendo ameaças aos funcionários e à família Civita. Uma contribuição interessante do livro, mas que é pincelada pela autora foi que o empresário Cesare decidiu deixar o país e tentar se instalar em São Paulo, mas Vittorio teria dito que não havia modos de utilizá-lo dentro da sociedade. Esse tema pouco explorado representa uma nova perspectiva sobre a relação dos dois irmáos e questionamentos acerca dos conflitos de interesse das empresas.

A partir dos anos de 1960, Cesare tentou se inserir no México, com a Mex-Abril. enviando o genro Giorgio de Angeli para 
gerir esse novo empreendimento. Claudia também recebeu uma versão nesse país, com ingredientes locais, com divulgação de material de escritores e comerciantes, assuntos sobre homens e roupas que podiam ser compradas em boutiques nacionais, além de belas mulheres da televisão e sobre o cinema do país. A Mex-Abril não se revelou tão próspera quanto as irmás e, no livro de Scarzanella, não houve muitas páginas dedicadas a essa investida de Cesare.

$\mathrm{O}$ destino da Abril argentina não se mostrou feliz desde os anos de 1970, explorado no encerramento do livro. Scarzanella enfatizou que o "capital social" de Cesare não foi o suficiente para transformar a editora argentina, empresa essencialmente familiar, em um empreendimento internacional. Os políticos, militares e lobistas teriam conquistados a Abril, como a própria autora afirmou no título do último capítulo.

$\mathrm{O}$ caso brasileiro foi mais frutífero. No ano de 2000, em seu cinquentenário, a empresa contava com 219 títulos nas bancas. Destarte, uma obra que demonstra as relaçóes sociais e os empreendimentos na imprensa latino-americano dentro da família Civita, se caracteriza como uma leitura imprescindível. Principalmente, ao se considerar o entrelaçamento da Abril argentina com o contexto político do país que influenciou a sorte da empresa. Para um leitor que busca conhecimento acerca da Abril no Brasil e no México, o livro não contempla um estudo detalhado, o título original justifica o motivo: Abril - De Perón a Videla: um editore italiano a Buenos Aires. O assunto está longe de se esgotar dentro da obra, sendo, dessa maneira, um instrumento interessante para multiplicar as pesquisas sobre o assunto na área de História.

O estilo de escrita e a divisão dos capítulos permitem uma leitura fluída, inclusive para aqueles que não são especialistas na área. A obra se destaca por ser o resultado de uma pesquisa intensa com grande diversidade de fontes, motivo que contribui para os debates em torno da editora Abril e também abre espaço para se pensar acerca das redes étnicas criadas pela família Civita.

\section{Referências}

ALMEIDA, Maria Fernanda Lopes. Veja sob censura: 1968-1976. São Paulo: Jaboticaba, 2009.

SCARZANELLA, Eugenia. Uma editora italiana na América Latina: o Grupo Abril (décadas de 1940 a 1970). Campinas. Editora da Unicamp, 2016. 